\title{
LA DIALÉCTICA ENTRE LA NACIÓN FAÚSTICA Y LA CIVILIZACIÓN MEDITERRÁNEA EN ESPAÑA: CLASES, PUEBLOS, NACIONES Y CESARISMO
}

\author{
Carlos Javier Blanco Martín \\ Universidad de Oviedo
}

http://dx.doi.org/10.5209/rev_NOMA.2012.v35.n3.42194

\begin{abstract}
Resumen: en este trabajo estudiamos los conceptos de Clase Social, Pueblo, Nación y Técnica en la obra de Oswald Spengler, La Decadencia de Occidente, y los ponemos en relación con la Historia de España. Entendemos que el actual estado español es el resultado de una dialéctica entre Naciones Faústicas y Civilización Mediterránea (antigua y arábiga).
\end{abstract}

Palabras clave.- Clase Social, Pueblo, Nación, Técnica, Nación Faústica, Civilización

The dialectic between the Faustian Nation and Mediterranean Civilization in Spain: classes, peoples, nations and Caesarism

\begin{abstract}
In this paper we study the concepts of Social Class, People, Nation and Technology in the Oswald Spengler's book, The Decline of the West, and put them in relation to the history of Spain. We understand that the current Spanish State is the result of dialectic between Faustian Nations and Mediterranean Civilization (Ancient, Arabic).
\end{abstract}

Keywords.- Social Class, People, National, Technics, Faustian Nation, Civilization

\section{Las Clases Sociales}

Las clases sociales, tal y como Oswald Spengler las entiende, son siempre el producto y el desenvolvimiento a partir de una diferenciación originaria: la nobleza y el sacerdocio. Se trata aquí de las clases originarias. A cada una de ellas le corresponde una dimensión fundamental del macrocosmos. A la nobleza, el tiempo: sobre el tiempo ejerce su poder, reclamándose heredera y asegurando para ella su continuidad, su dominio venidero. Al sacerdocio le conviene el espacio: el afán de abarcar, de extenderse sobre el medio y llegar lejos. Una Cultura, cual planta que desarrolla su ciclo, que extiende sus funciones vitales en una biocenosis (el planeta y la Historia Universal) es siempre, en parte, el resultado de la lucha y la cooperación (de la dialéctica, en suma) entre estas dos clases originarias, que se corresponden con dos orientaciones anímicas completamente diferentes, pero que pueden entretejerse.

En la Cultura faústica, la Europa cristiana del gótico (naciente en la rebelión de Covadonga de 722, en el feudalismo postcarolingio, en la síntesis del romanogermanismo) se plasma esta dialéctica por medio de las figuras de la Catedral y el Castillo. Estas dos moles de piedra son símbolos genuinos de la cultura faústica, del cristianismo gótico, de la Europa juvenil que tuvo que 
desprenderse de las pseudomorfosis antiguas (las formas decadentes o ajenas: mediterráneas, romanas, moras) para ser ella misma.

La Catedral como símbolo elegido por Spengler para el sacerdocio cristianogótico representa la metafísica hecha piedra. Toda religión es una metafísica y una orientación en el espacio. "La ley moral dentro de mí y las estrellas encima de mí", todo el que así piense, es un sacerdote en el sentido espiritual, ya que no en el rito. Arriba, adonde apuntan las agujas del templo, el cielo; abajo, donde los pilares de la mole de piedra enraízan, de donde brotan los hijos de la tierra (el humus, el hombre). Pero el sacerdote es espíritu y es vigilia: abarca con los ojos la tierra extensa ya defendida, ya conquistada. La Catedral fue posible por el Castillo.

El Castillo es la plasmación pétrea de la sangre, del alma de la nobleza. La perduración en el existir, el sentido genealógico (de dónde venimos) y el dinástico (hacia dónde), la espada en la mano y el dominio que tiene la sangre sobre los razonamientos y las justificaciones. El noble crea el derecho, el clérigo lo codifica. Las dos clases originarias fundaron Europa, pero lo hicieron, además, de forma absolutamente inconsciente. Dentro del juego de conceptos manejado por Spengler, es este concepto de "la sangre" el que describe de la manera más gráfica, el poderío inconsciente, el carácter fluido y como de torrente con el que un tipo de alma puede crear una nación. Mientras que el sacerdocio es, per se, universal, movedizo, la nobleza es vegetal en el sentido de que arraiga en un suelo madre. Incluso las noblezas más viajeras (emigrantes o conquistadoras, pues en esto no hay diferencias sustanciales) llevan consigo los efectos de la "comarca madre" durante muchas generaciones. Este "poder de la sangre" guarda muy poca relación con las modernas categorías de la genética. No lo puede descubrir el biólogo en el ADN, y no se refiere a las razas en el sentido anatómico. Seria mucho más correcto situar este concepto en la línea de un Inconsciente Colectivo: una fuerza misteriosa, inasequible a la razón, que dota de "formas primigenias" a los pueblos sucesores de aquella clase.

\section{La aldea}

El noble es, en realidad, la quintaesencia del aldeano. Todavía en las comarcas europeas menos afectadas por el poder de la ciudad, existen rasgos de nobleza en la clase aldeana. La pobreza material, el apartamiento del poder, de sus luchas y de sus centros, impide al observador superficial reconocer en los ejemplares más puros de la clase aldeana el arquetipo de la clase noble. Por ejemplo, en el norte de España, la casa aldeana sólo conoce diferencias materiales (tamaño, riqueza) con respecto a la casona noble. Ambas son una misma especie, muestra visible de "una raza".

Spengler señala con acierto la continuidad entre la casona de la Europa nórdica (que incluiría la España cantábrica) y el Castillo. Una humilde casa de labriegos, piedra y madera que forman un microcosmos en medio del mundo grande, es ya -en el espacio- un castillo que se cierra ante la naturaleza circundante. La presión humana no es tan grande como acontece en los 
pueblos campesinos mediterráneos. En éstos, la estructura de la polis ya está presente en un villorrio de doscientas almas. Las casitas blancas se apretujan alrededor de su ágora. El labriego nórdico, en cambio, levanta sus "almenas" ante una naturaleza que, sin sus cultivos y rebaños, sería salvaje: el bosque, el monte son como feudos y ramificaciones del pequeño reino. La casería asturiana y montañesa, el caserío vasco, forman un continuum con la Europa fáustica, nación de naciones formada por aldeas dispersas que posibilitaron la ciudad, hasta que se cambiaron las tornas hacia el siglo XII, y la ciudad se igualó al campo, hasta llegar a subordinar y esclavizarlo. La Europa medieval, la del Castillo y de la Catedral, fue una Europa plagada de casas labriegas, de granjas que, en la medida en que eran autosuficientes y disponían de libertades y privilegios, emulaban castillos y pequeños reinos. Esto es así especialmente en el norte hispánico, donde las peculiaridades de la Reconquista en la Alta Edad Media pudieron dar lugar a toda una sociedad de hombres libres, caballeros a la vez que labriegos. Todavía en las casonas norteñas, casas de aldea, se esconden los escudos hidalgos de piedra entre la hiedra o bajo la cal y el cemento, o, al menos, se divisa el hueco que en sus días ocupó. Todavía es frecuente que en las caserías asturianas haya un nombre para la unidad (que no es solo unidad agropecuaria o un edificio, sino Institución), un nombre de la casería, que comprende edificios, tierras, derechos diversos, y que se conserva a lo largo de las generaciones con independencia de sus propietarios. Se trata de un nombre distinto al de la familia que transmite sus derechos a los sucesores, de la misma manera que en un Reino puede cambiar la dinastía ocupante del trono. ${ }^{1}$

El noble nace, pues, del aldeano. Es una clase primigenia, pero destinada a hacer la Historia. Al igual que el noble tiene que movilizar a los aldeanos para hacerlos entrar en la Historia, el noble forja la Nación, convirtiendo un Pueblo en empresa lanzada a un sino. Con esta distinción entre Pueblos y Naciones, Spengler se alza contra la corriente romántica que, según nos parece, nuestro filósofo interpreta como corriente "populista" (nunca mejor dicho), esto es, niveladora. Al gozar todo Pueblo de su propia idiosincrasia, al contar con un tacto y estilo propios -cosa que Herder y los románticos descubrieron- se podría caer en una especie de prejuicio igualitarista a propósito de los Pueblos de Europa: muchos de ellos hubieran sido pueblos primitivos o "aldeanos" de no haber sido por el empuje de una "aristocracia" de pueblos que empujan y lideran a los otros, los absorben, conquistan o los fuerzan a despertar de su inconsciencia vegetal. Fue la nobleza -algunos aldeanos armados- de cierto número reducido de pueblos la que edificó naciones. Las naciones faústicas se fueron forjando en el largo y juvenil periodo gótico. Ese periodo que el prejuicio ilustrado nos presentó como una noche, Spengler nos lo muestra en cambio como una primavera. Por eso, prácticamente hasta la época de las guerras napoleónicas, la nobleza, incluso la baja nobleza acurrucada en su caserón aldeano, obró siempre sintiendo la nación como cosa suya, creación de sus antepasados y propiedad que defender.

\footnotetext{
${ }^{1}$ Blanco (2009): Teoría de los círculos concéntricos de la Nación Astur: casería, conceyu, Xunta, N'ast: cartafueyos d'ensayu, №. 3, 2009, 19-30
} 


\section{La tercera clase, la burguesía y la chusma}

El tercer estamento, frente a nobles y clérigos, Spengler nos lo presenta informe. Antes de la homogeneización que trajo consigo el industrialismo y la conciencia de clase proletaria, el tercer estado se arroga el título de "pueblo", cuando en realidad es el poder burgués ayudado por todo un decantado y detritus de diversos sectores sociales: nobles arruinados y decaídos moralmente, comerciantes en bancarrota, tenderos ambiciosos, obreros ocasionales, jornaleros del campo fugados a la ciudad, pasantes, delincuentes. Spengler, con su método de las correspondencias, encuentra paralelos en la plebe romana, en los habitantes felahs de pueblos que dejaron de ser naciones, en parásitos y beneficiarios de la política del panem et circensis que han practicado los grandes estados decadentes. En ocasiones críticas, en el momento ascendente de una revolución, esta masa móvil, desocupada y pendenciera, se pone a la cabeza de las clases sanas y justamente descontentas, y se apoderan azarosamente del poder. Entonces comienza su jacobinismo, el terrorismo del Estado revolucionario, que siempre es el poder del lumpen, que ya llevaba tiempo afilando sus cuchillas. Todos los Robespierre que la Historia ha parido son oportunistas y mediocres que usurpan al verdadero pueblo sus derechos.

Se dice que con 1789 nace "el concepto de nación". Se habla de la Edad Media y del Antiguo Régimen como de unas épocas meramente dinásticas, en las que había reinos y casas soberanas, pero no naciones. Pero a esta tesis oficial de la historiografía vigente, especialmente la que ha sido escrita desde perspectivas de izquierda marxista y "progresista" tal vez cabría oponer la tesis justamente contraria. Que con el escenario revolucionario y las oleadas de constitucionalismo liberal, la poderosa fuerza (que yo creo que Spengler calificaría de cósmica) muere la Nación faústica y se vislumbra el cesarismo en el horizonte.

En efecto, con 1789 comienza la Civilización Europea, puesto que decae la Cultura Faústica. Tras la Revolución viene el napoleonismo y, tras éste periodo, el cesarismo. Se puede vaticinar, de acuerdo con nuestro filósofo, que el siglo que nos aguarda es el siglo de lo informe. Poderes informes, masas de pueblos felahs también informes y un césar que los utilizará como única salida a la anarquía creciente. El comienzo de la Civilización (en el sentido preciso de decadencia de la Cultura) es el fin de las naciones. La tradición jacobina y francesa quiere confundir naciones, estados, pueblos o, como tanto se dice ahora, la ciudadanía... Pero la Nación no es nada de esto. Grandes estados canónicos en Europa han sido, y serán siempre, plurinacionales. Muchos pueblos han sido, son y serán, a su vez, componentes esenciales de Estados de larga duración, cuya presencia en la Historia nunca se ha dado con vocación de independencia. Los filósofos de medio pelo que Nietzsche, significativamente, clasifica como los propaladores de las "ideas modernas" (Montesquieu, Rousseau) y los doctrinarios que les siguieron, han guardado silencio sobre el carácter necesariamente elitista y nobiliario que siempre ha presentado el concepto de Nación: como pueblo noble, dirigido por la aristocracia más voluntariosa y conocedora de su sino, que se lanza hacia la Historia. Un pueblo que hace Historia es Nación, y para ello se dota de medios 
militares y jurídicos adecuados para esta empresa. Pero la masa informe actual de la "ciudadanía europea" no puede ser ya sustrato de Nación ninguna.

"Un pueblo existe realmente sólo con relación a otros pueblos. Pero por eso la relación natural, racial entre ellos es la guerra. Es éste un hecho que las verdades no pueden alterar. La guerra es la política primordial de todo viviente, hasta el grado de que en lo profundo lucha y vida son una misma cosa y el ser se extingue cuando se extingue la voluntad de lucha. Viejos vocablos germánicos, para indicarlo, como orrusta y orlog, significan seriedad y sino, en oposición a broma y juego; es más bien una sublimación que una diferencia esencial. Y si es cierto que toda alta política quiere substituir la espada por otras armas más espirituales y la ambición del hombre de Estado en la cúspide de todas las culturas consiste en no necesitar ya casi de la guerra, queda siempre la primordial afinidad entre la diplomacia y el arte militar: el carácter de la lucha, igual táctica, igual astucia guerrera, la necesidad de fuerzas materiales en retaguardia, para dar peso a las operaciones. También es el fin idéntico: el crecimiento de la propia unidad vital-clase o nación-a costa de las demás. $Y$ todo intento de eliminar ese elemento racial conduce tan sólo a desviarlo hacia otra esfera; en vez de actuar entre Estados actuará entre partidos, entre comarcas, y si también aquí se extingue la voluntad de crecimiento, actuará entre los séquitos de aventureros a quienes voluntariamente se somete el resto de la población". [LDO, II, 677]. ${ }^{2}$

En la época cesarista, cuando el mundo entero se vuelve informe, las naciones pierden formas, los pueblos se vuelven felahs, y las masas ya no ven como propios los asuntos de defensa fronteriza y de orden interior, surgen líderes que todavía exhiben rasgos de "raza". Éstos se hacen con el poder con tal que obtengan partidarios armados y haya gentes que conozcan el valor de la lucha

\footnotetext{
${ }^{2}$ Las siglas LDO hacen referencia a la versión castellana de La Decadencia de Occidente, Espasa Calpe, Madrid, 1998. Tomo II, traducción de don Manuel García Morente. La versión alemana consultada se cita así: DUA, iniciales de Der Untergang des Abendlandes, Ed. Beck, Munich, 1922.
}

Ein Volk ist wirklich nur in bezug auf andere Völker. Aber das natürliche, rassehafte Verhältnis zwischen ihnen ist eben deshalb der Krieg. Das ist eine Tatsache, die durch Wahrheiten nicht verändert wird. Der Krieg ist die Urpolitik alles Lebendigen und zwar bis zu dem Grade, daß Kampf und Leben in der Tiefe eins sind und mit dem Kämpfenwollen auch das Sein erlischt. Altgermanische Worte dafür wie orrusta und orlog bedeuten Ernst und Schicksal im Gegensatz zu Scherz und Spiel; das ist eine Steigerung, nichts dem Wesen nach Verschiedenes.

Und wenn alle hohe Politik der Ersatz des Schwertes durch geistigere Waffen sein will und der Ehrgeiz des Staatsmannes auf der Höhe aller Kulturen dahin geht, den Krieg fast nicht mehr nötig zu haben, so bleibt doch die Urverwandtschaft zwischen Diplomatie und Kriegskunst bestehen: der Charakter des Kampfes, dieselbe Taktik, dieselbe Kriegslist, die Notwendigkeit materieller Kräfte im Hintergrund, um den Operationen Gewicht zu geben; und auch das Ziel bleibt das gleiche: das Wachstum der eignen Lebenseinheit - Stand oder Nation - auf Kosten der andern. Und jeder Versuch, dies rassemäßige Element auszuschalten, führt nur zu seiner Verlegung auf ein andres Gebiet: statt zwischen Staaten zwischen Parteien, zwischen Landschaften, oder wenn auch da der Wille zum Wachstum erlischt, zwischen den Gefolgschaften von Abenteurern, denen sich der Rest der Bevölkerung freiwillig fügt. [DUA,Il, 549-550] 
militar o sientan pasión por ella. Los pacifistas de todas las épocas solo aspiran a ser esclavizados más tarde o más temprano, según Spengler. El crecimiento de la unidad vital [das Wachstum der eignen Lebenseinheit] requiere de esos hombres "de raza". En la historia de los hombres hay un factor racial que, si no encuentra la forma plena para su expresión (su voluntad de dominio), que es la Nación, habrá de canalizarse en luchas y disensiones mucho más destructivas. El aspecto verdaderamente creador de la guerra acontece cuando la fuerza de la sangre pone "en forma" a los pueblos, los hace entrar en la Historia.

Occidente, tras las dos guerras mundiales, la fase de los "Estados en lucha", y una vez superada la estabilidad de la guerra fría, que suponía el equilibrio -aun con mucho juego de farol- entre dos concepciones económicas del mundo (capitalismo y comunismo), se enfrenta hoy a unos años decisivos. Bien pronto puede llegar el día de su esclavitud una vez que la nueva clase sacerdotal de los tiempos decadentes esgrime conceptos, constituciones, Derechos Humanos, "verdades", pero se vuelve autista, ciega y sorda ante los hechos. La gruesa y monumental obra de Spengler está recorrida por este pesimismo y este espíritu profético: Occidente no es la única ni la mejor (¿por qué valorar los hechos? ¿qué valoraciones hacen los hombres de otras civilizaciones sobre la nuestra?). Nació y un día morirá. Ya está muriendo en realidad. Quizá parte de su muerte consista en no querer actuar en función de los hechos, lo que equivale a decir: no querer actuar en absoluto. Se anuncian nuevas y más definitivas guerras en el horizonte. Que la guerra hace a los hombres y a los pueblos, y también los deshace, es un hecho contra el que nada pueden las verdades [Das ist eine Tatsache, die durch Wahrheiten nicht verändert wird]. Los euroburócratas, los neoliberales, la "izquierda", los banqueros y los sindcalistas, los funcionarios y pensionados de las ONGs, así como ecologistas y conservadores: todos, la inmensa mayoría de los hombres de Occidente que creen poseer el poder o se benefician de él ya son "hombres de verdades", no "hombres de hechos". Al no haber aristocracia solo nos resta un sacerdocio laico, vulgar hasta el extremo, tecnocrático y pacifista, excrecencia superestructural del capitalismo avanzado. Una banda de aventureros, con tal que amen el riesgo y el peligro, podría quitarlos de en medio. Y lo mismo podríamos decir de los nuevos "bárbaros". En las puertas de Occidente, o en los confusos términos de su periferia, asoman nuevas potencias dispuestas a tragarse esta civilización, aunque desde el punto de vista emic de estos "bárbaros", de lo que se va a tratar, simplemente, es de coger el relevo: hacer el papel de herederos. Al igual que entre un godo del siglo $\mathrm{V}$ y un romano de la misma época ya había diferencias menores, esto sucede en las grandes urbes de rascacielos de Shanghai, Moscú, Sao Paulo, etc. ¿Quién negará a esos habitantes de la gran urbe de la potencia "emergente" su condición de occidental? Pues ya hace tiempo que occidental significa, por ejemplo, consumir música pop, no escuchar a Mozart, consumir en una cadena de hamburguesas, no leer a Homero.

En el panorama actual se ven por doquier los síntomas de la decadencia. La democracia es, como en otras civilizaciones y épocas, el poder del dinero. Este cesarismo es producto de los periodos revolucionarios, y en ella es fundamental el papel de la hez o la chusma: 
"Pero debe añadirse ahora un elemento, que aparece por primera vez y que en las luchas de la fronda, de la revolución inglesa, de la primera tiranía, no había existido, pero que ahora representaba una fuerza: ese elemento que en todas las civilizaciones recibe el inequívoco nombre de hez, populacho, plebe. En las grandes ciudades-que ahora lo deciden todo, siendo el campo a lo sumo capaz de tomar actitudes ante los hechos consumados, como demuestra todo el siglo XIX —reúnese una masa de población desarraigada, que no pertenece a ningún circulo social. Esos hombres no se sienten unidos a una clase, ni pertenecientes a un grupo profesional-y en el fondo de su corazón ni siquiera a la clase trabajadora, aunque están obligados a trabajar. Por instinto pertenecen a esta hez gentes de todas las clases y grupos, aldeanos desarraigados, literatos, hombres de negocios arruinados, y, sobre todo, nobles decaídos y desviados, como nos lo muestra con tremenda claridad la época de Catilina. Su poder es mucho mayor que su número, pues siempre están situados en la proximidad de las grandes decisiones, siempre dispuestos a todo, sin el menor respeto al orden, incluso al orden indispensable en un partido revolucionario. Estos hombres son los que dan a los acontecimientos el poder aniquilador que distingue la revolución francesa de la inglesa y la segunda de la primera tiranía. La burguesía se aparta, con verdadero terror, de esta masa, de la que ansia distinguirse - a uno de estos actos de repulsa, al 13 de Vendimiario, debe Napoleón su subida-; pero los limites no se pueden trazar en el bullicio de los hechos y dondequiera que la burguesía moviliza contra las viejas instituciones su fuerza de choque, harto escasa con relación al número (digo escasa porque en cada momento resulta problemática la unidad interna), siempre esa masa se infiltra en sus filas y se coloca delante y decide el éxito en su mayor parte, sabiendo luego utilizar la posición ganada para su provecho propio, muchas veces con el apoyo ideal de las personas cultas, que se sienten fascinadas por los conceptos y por el apoyo material del dinero, los cuales saben desviar el peligro sobre la nobleza y la clase sacerdotal." [LDO, I, 616-617]..$^{3}$

\footnotetext{
${ }^{3}$ Aber dazu kam von hier an ein Element, das in den Kämpfen der Fronde und also der englischen Revolution und der ersten Tyrann is noch gar nicht vorhanden war, nun aber eine Macht darstellte: das was man in allen Zivilisationen eindeutig als Hefe, Mob oder Pöbel bezeichnet. In den großen Städten, die jetzt allein entscheiden - das flache Land kann höchstens zu vollzogenen Ereignissen Stellung nehmen, wie das ganze 19. Jahrhundert beweist) - sammelt sich eine Masse wurzelloser Bevölkerungsteile an, die außerhalb jeder gesellschaftlichen Bindung stehen. Sie fühlen sich weder einem Stande zugehörig noch einer Berufsklasse - im innersten Herzen auch nicht der wirklichen Arbeiterklasse, obwohl sie zur Arbeit gezwungen sind ; dem Instinkt nach gehören Glieder aller Stände und Klassen dazu, entwurzeltes Bauernvolk, Literaten, ruinierte Geschäftsleute, vor allem aus der Bahn geratener Adel, wie die Zeit Katilinas mit erschreckender Deut- lichkeit lichkeit gezeigt hat. Ihre Macht übersteigt bei weitem ihre Zahl, denn sie sind immer am Platze, immer in der Nähe der großen Entscheidungen, zu allem bereit und ohne jede Achtung vor irgend etwas Geordnetem und sei es selbst die Ordnung innerhall» einer Revolutionspartei. Sie erst geben den Ereignissen die vernichtende Gewalt, welche die französische von der englischen Revolution und die zweite von der ersten Tyrannis unterscheidet. Das Bürgertum wehrt sich mit wahrer Angst gegen diese Menge, von der es sich unterschieden sehen will - einem dieser Abwehrakte, dem 13. Vendemiaire, verdankt Napoleon seinen Aufstieg - aber die Grenze läßt sich im Gedränge der Tatsachen nicht ziehen und überall, wo das Bürgertum seine im Verhältnis zur Zahl geringe Stofskraft gegen die älteren Ordnungen ansetzt, gering, weil die innere Einheit in jedem Augenblick auf dem Spiele steht, hat sich diese Masse in seine Reihen und an die Spitze gedrängt, die Erfolge zum weitaus größten Teil erst entschieden und die gewonnene Stellung sehr oft für sich zu behaupten gewußt, und zwar häufig mit der ideellen Unterstützung durch die
} 
Varios son los términos que designan, en LDO a esta chusma oportunista [Hefe, Mob, Pöbel]: su propio carácter heterogéneo impide hablar de una clase, y menos de una clase primigenia, que solamente está constituía por la nobleza (Adel) y el Sacerdocio (Priestertum). Ni siquiera la burguesía (Bürgertum) quiere tratos con la chusma, pese a que necesitó de ella en el momento en que fue preciso conquistar el poder a costa de los aristócratas y del clero. Con la chusma en primera fila, se anuncian la falta de juego limpio, la pérdida interna de las formas, la degradación del sentido moral, el tacto, la moderación. La masa sin raíz, que habita en las ciudades y se amalgama sin formar una clase obrera (Abeiterklasse) ni profesional (Berufsklasse) deshace las formas culturales, prepara la decadencia y pone el poder en manos de un arribista lo suficientemente ambicioso. El juego de formas y liturgias que se dará en llamar, después del periodo revolucionario y del napoleonismo, la "democracia", no será ya más que el crudo poder del dinero unido a la más profunda desintegración del pueblo.

Se trata de la voluntad de poder de los partidos y el cesarismo de los partidos erigido para que de veras no exista un "poder del pueblo", y para que a través del sistema de partidos triunfe el dinero. Ya en los ejemplos históricos, especialmente los correspondientes a los comicios en Roma, se observa que Democracia es solo y únicamente Plutocracia. A partir del siglo XIX, momento en el que la burguesía por fin se hace llamar "pueblo" y organiza la sociedad, precisamente desorganizando a las naciones y anulando a las clases primordiales (nobleza y sacerdocio), el capitalismo y sus superestructuras plutocráticas extienden su dominio universal. Los propios "partidos" nobiliarios y clericales deben aburguesarse, actuar bajo la máscara de que ellos representan un sector del "pueblo". Y, en el momento en que la industrialización comienza a dotar de contingentes obreros a los países, crecen los partidos socialistas -aun bajo la fraseología de la Revolución y la táctica de las barricadas- que son partidos burgueses en lo más hondo.

\section{Nacionalismo}

El nacionalismo burgués, el que nace con la Revolución y con la contraofensiva que ella y Napoleón representaron, es un producto "romántico". Mezcla la nostalgia por la aldea con el sentido plutocrático del dinero. El nacionalismo burgués, en el fondo, es el nacionalismo de los "ciudadanos". Representa la fantasía de un "pueblo" en el que se desdibujan las clases y sus fronteras internas. Sin embargo, Spengler sostiene que la nación es el producto de una clase primordial, la nobleza. Frente al universalismo que es la tendencia del sacerdote, la nobleza habla de la nación como "suya".

Gebildeten, welche das Begriffliche daran fesselte, oder der materiellen durch die Mächte des Geldes, welche die Gefahr von sich auf Adel und Priestertum ablenkten. [DUA, II, 498-499]. 
"En el campo sin ciudades, la nobleza fue la primera que representó a la nación en sentido elevado. Los aldeanos, sin historia, «eternos», eran pueblo antes de iniciarse la cultura: siguen siendo pueblo primitivo en rasgos muy esenciales y sobreviven a la forma de nación. La «nación», como todos los grandes símbolos de la cultura, es posesión íntima de pocos hombres. Hay que nacer para ello, como se nace para el arte y la filosofía. Hay en esto algo que corresponde a la diferencia entre creador, aficionado y lego; y lo hay tratándose de la polis antigua, como tratándose del consensus judaico o de un pueblo occidental. Cuando una nación se enciende en entusiasmo para luchar por su libertad y su honra, siempre es una minoría la que «entusiasma» a la multitud, en el propio sentido de la palabra. ¡El pueblo despierta!- Estas palabras son mucho más que un tópico habitual. Manifiéstase ahora realmente la vigilia del conjunto. Todos esos individuos que ayer aún andaban presos en un confuso sentimentalismo aplicado a la familia, a la profesión, quizá a la aldea natal, son hoy, de repente, ante todo hombres de su pueblo. Su sentir y su pensar, su yo y con él el conjunto unitario en ellos, se ha transformado profundamente; se ha hecho histórico. Entonces es cuando el aldeano inhistórico se torna miembro de la nación; para él despunta ahora una época en que vive la historia y no se limita a verla pasar." [LDO, II, 286]. ${ }^{4}$

El romanticismo había mostrado las raíces de cada nación en un pueblo primitivo (Urwolk). Spengler rechaza la ahistoricidad de este enfoque. El aldeano inhistórico (geschichtlose Bauer) no constituye la nación, por más que sea la base material de ella, de la cual brotan las clases primordiales (nobles y sacerdotes). Son los nobles, quintaesencia de los aldeanos, los que encienden la pasión (Begeisterung) por la nación. En toda alborada de la Cultura [der Anbruch der Kultur], se observa cómo una clase noble da el paso desde lo eterno a lo histórico. La fuerza de la sangre lo pide, pero la vigilia -aunque sea semiconsciente- lo exige con firmeza. La nación constituye la empresa que la sangre más noble de un pueblo se exige, en un impulso hacia la Historia. La comarca madre de donde brota un pueblo se amplia con una serie de conquistas, y se afirma ante enemigos exteriores. Entonces un pueblo bien acaudillado, consigue aliarse, fundirse 0 , sencillamente, dominar a los demás pueblos que le rodean y construye así la nación. Los "pueblos primitivos", simplemente aldeanos, si quedan reducidos a un margen o se desacostumbran

\footnotetext{
${ }^{4}$ Im stadtlosen Lande war es der Adel, welcher zuerst die Nation in einem höheren Sinne vertrat. Das Bauerntum, geschichtslos und „ewig", war Volk vor dem Anbruch der Kultur; es bleibt in sehr wesentlichen Zügen Urvolk und es überlebt die Form der Nation. „Die Nation" ist wie alle großen Symbole der Kultur innerer Besitz weniger Menschen. Man wird dazu geboren wie zur Kunst und zur Philosophie. Es gibt auch da etwas, das dem Unterschied von Schöpfer, Kenner und Laien entspricht und zwar in einer antiken Polis ebenso wie im jüdischen consensus und in einem Volk des Abendlandes. Wenn eine Nation in Begeisterung aufsteht, um für ihre Freiheit und Ehre zu kämpfen. Ist es immer eine Minderheit, welche die Menge im eigentlichsten Sinn des Wortes „begeistert". Das Volk wacht auf - das ist viel mehr als eine Redensart. Das Wachsein des Ganzen tritt wirklich erst jetzt in Erscheinung. Alle diese einzehien, die gestern noch mit einem Wirgefühl einhergingen, das sich lediglich auf die Familie, den Beruf, vielleicht den Heimatort erstreckte, sind heute plötzlich vor allem Männer ihres Volkes. Ihr Fühlen und Denken, ihr Ich und damit das "Es" in ihnen hat sich bis in die Tiefe umgewandelt: es ist historisch geworden. Dann wird auch der geschichtslose Bauer Glied seiner Nation und es bricht für ihn eine Zeit an, in der er Geschichte' erlebt und nicht nur vorüberziehen läßt. [DUA, II, 221-222].
} 
al uso de las armas, se congelan en el tiempo, semejan ser simple naturaleza. En ellos, los ritmos son los ritmos cósmicos: los de la cosecha, las estaciones del año, nacimiento, matrimonio, muerte... La tensión de un pueblo afanoso de botín y conquistas, es algo que les resulta ajeno, desconocido, odioso. Las naciones son empresas políticas, son ya Historia y no Naturaleza.

La nación, propiamente, es la nación faústica: su comarca es esa pequeña y abigarrada extremidad de la enorme Asia, y que no es otra que Europa. Para Spengler las otras culturas que nos son más cercanas (la mágica del consensus, la antigua de la polis) no pueden realizar esa síntesis de poder de la tierra (influencia indeleble del suelo y el paisaje), dialéctica de campo y ciudad, fuerza psíquica de la lengua. En Europa es más poderoso y de mayor hondura y alcance, el vínculo sanguíneo, terráqueo y idiomático. Europa será federación o imperio multinacional o no será nada en el futuro sucesivo, salvo un gran campo de esclavos.

\section{Cantábrico versus Mediterráneo. Naciones faústicas (o culturales) frente a civilizaciones}

El hombre mágico del consensus, ya viva en un desierto o en las callejuelas de una gran ciudad, es ante todo un fiel de una comunidad universal envuelta por la gran bóveda que separa el cielo y la tierra, el espíritu y la material, la luz y la tiniebla. A su vez, el hombre antiguo (y lo que de él tiene todavía el hombre mediterráneo), no siente como suya la nación tanto como la ciudad, entendida como cuadrícula que se delimita frente al campo. Incluso si él es campesino, su referencia político-económica es la urbe que, ya desde tiempos antiguos, sojuzga y estrangula al campo hasta el punto de haberle cambiado su fisonomía en tiempos antiguos. El paisaje mediterráneo es, en este sentido, producto absoluto de la civilización: su desecación, su irrigación, su ordenamiento "euclídeo" por referencia a la urbs. Por el contrario, el paisaje cantábrico-atlántico aún conserva restos o islas de virginidad, de los tiempos no tan lejanos en que la urbe no contaba con poderío suficiente para domeñar las selvas húmedas ni conquistar los agrestes montes.

La incomprensión mutua entre las dos culturas (mejor dicho, entre las culturas norteñas, atlánticas, y las civilizaciones mediterráneas, sureñas) ya fue por nosotros subrayada de forma un tanto impresionista en la obra Casería y Socialismo:

“a) ¿Cómo veían los mediterráneos (fuentes clásicas) a los celtas (paradigma genérico de la periferia atlántica, de la Iberia/Hispania meridional) y pueblos indoeuropeos septentrionales [...]? Los concebían como insumisos, aguerridos, temerarios ante la muerte por creer en la inmortalidad (o en la reencarnación), soñadores, imaginativos, amantes de la palabra, maestros en retórica.

b) Características que impone la latinización de Europa: fortísimo patriarcado (la mujer, un objeto); terratenientes en el agro; muchedumbre apelmazada en las ciudades; el cosmopolitismo de las grandes urbes mediterráneas (Helenismo decadente, Imperio Romano) se asienta sobre una gran masa de 
población que en realidad, vive en el umbral de la pobreza; su moral sólo es externa y estricta, basada en la observación pública de los actos de los demás ciudadanos. El quehacer mayoritario podría denominarse tráfico mercantil y tráfago, rasgos propios de la llamada Alta Civilización. Se vive más en la calle, en el seno de estructuras urbanas, cosa que las civilizaciones clásicas mediterráneas comparten con los pueblos árabes norteafricanos (Magreb), los pueblos semitas (fenicios, cartaginenes, hebreos) y otros pueblos de la Antigüedad (etruscos, íberos levantinos, muy helenizados). Hoy todavía este tipo de ciudades del ámbito mediterráneo son un hervidero mercantil, muy desligado de la vida rural, un gran mercado o zoco donde todo se comercia, pero sólo en los cinturones industriales (antiguamente los barrios de artesanos de las urbes) se produce." [CS, 60-61]. ${ }^{5}$

En Casería y Socialismo hemos buscado una síntesis atrevida entre el materialismo histórico y la morfología histórica, esto es, entre Marx y Spengler. Aunque esta obra es solo un bosquejo preliminar, en ella ya ofrecemos algunas bases comparativas entre la España norteña y la sureño-levantina. La Antigüedad, primero, y la Reconquista, después, sientan las bases del "nacionalismo periférico" tan denostado por el nacionalismo español de hoy. ¿Por qué hay cierto sentimiento, y a veces movilización política y cultural, en la línea de un regionalismo o nacionalismo en las comunidades norteñas frente al resto? El factor del idioma es un espejismo romántico. Ya hemos visto que el paisaje, la sangre, la casa aldeana, la experiencia histórica de haberse formado como pueblo y aun como nación es lo decisivo.

"[...] surge, con todo su esplendor, el modelo de granja, la casería, que hundía sus raíces en toda Europa, nada menos que en la Edad de Hierro. La franja norte peninsular, claramente indoeuropea, conoció este modelo de explotación desde tiempos prehistóricos, aunque fueron las distintas superestructuras políticas las que tallaron o recortaron sus rasgos básicos. Este modelo de granja es común en lo esencial con el modelo atlántico y centroeuropeo. Por naturaleza es ajeno a todo género de esclavitud o de servidumbre feudal, y supo sobrevivir frente a estas pseudomorfosis impuestas. [...]. Ástures, cántabros, galaicos, vascones, y en definitiva, todos los demás pueblos célticos de la Europa atlántica, renacieron con la decadencia de Roma y su extinción, por más que dejaron estructuras rígidas o intrusiones, a modo de cuerpos extraños, que sólo los siglos en su lento transcurrir, podrán asimilar o, finalmente, secretar. [...] otra idea de Spengler, [...], es precisamente ésta: la casa del campesino como documento más genuino 0 , si quiere, esencial, para la inteligencia del modo de ser de un pueblo. Mirad cómo son sus casas, y añado, sus pautas generales de habitación en la naturaleza, de asentamiento en un territorio, y comprenderéis su antropología. La casa campesina asturiana es ese documento vivo, que junto a la música, los modos de trabajo y ocio, los mitos, y mil elementos más, nos ponen en contacto con los círculos culturales atlánticos, dicho esto sin querer minusvalorar los contactos e influjos sureños. La casa aldeana, su organización en aldeas y villas, la antiquísima democracia concejil, el aprovechamiento ecológico de los recursos, respetuoso con el medio y garante de su sostenibilidad, rasgos típico de la Asturies secular, son

\footnotetext{
${ }^{5}$ Blanco, C.: (2008): Casería y Socialismo. Nación Asturiana y Nacionalismo Marxista. Edit. Glayíu, Asturies. Citamos con las iniciales: [CS]:
} 
propiedades incompatibles con una generalización de la servidumbre o la esclavitud, aunque éstas se hubieran dado de forma minoritaria estas instituciones en el pasado. Si echamos un vistazo comparativo, esta casería, unidad de habitación y producción, no tiene nada que ver las pautas de vejación de la naturaleza, de explotación irrespetuosa con el medio, que desde antiguo ya se constata en los ámbitos mesetario, sureño y levantino. ${ }^{6}$ [CS, 9394]

Conviene no relegar a la Etnología la cuestión de por qué en un Estado hay sentimientos nacionalistas, o fundamentos "objetivos" para los mismos, en ciertas regiones y en otras no. Debe acudirse a una Filosofía de la Historia o, mejor, como propone Spengler, una Morfología de la Historia. Hacer esto no debe implicar una toma de postura política concreta (separatismos, independentismos, etc.). Nuestro propósito ahora no es otro que la comprensión. Que el actual Estado Español sea, en última instancia, resultado de una Reconquista (un largo proceso de ocho siglos de historia) es un hecho, no una "verdad". Recuérdese la distinción spengleriana entre hechos y verdades. Sería muy hermoso, especialmente para la jacobino centralista y para el apóstol de los Derechos Universales, decretar (como es la pretensión última de todo racionalista) la uniformidad de España. Este Estado que hemos traído aquí como ejemplo es resultado de una dialéctica entre cultura $y$ civilización. Los sentimientos nacionalistas o regionalistas del Norte, estén o no organizados políticamente, no son "periferia", propiamente. Son expresión de la cultura y de la raza (raza, en el sentido spengleriano, que alude más bien a una condición espiritual). La reacción de rechazo que despiertan (políticamente articulada) desde el centralismo madrileño o desde un nacionalismo español, no muy detectable antes de $1868^{7}$, por el contrario, guarda más relación con la pertenencia a la civilización. El orbe mediterráneo es conocedor de unas ondas de larguísima duración, y las gentes que en su esfera habitan son herederas semiconscientes de las viejas civilizaciones "antiguas" y "arábigas". En todo esto que decimos nos cuidamos mucho de hacer ahora un juicio de valor. No hay una forma de vida mejor que otra, y un individuo tomado al azar no es "representante prototípico" de ninguna cultura o civilización, de ningún tipo ideal de raza o nacionalidad. Tampoco existen, en lenguaje spengleriano, como protagonistas verdaderos de la Historia los "pueblos". Cuando hoy hablamos del "pueblo vasco" o del "pueblo murciano" hace ya tiempo que formamos en nuestra cabeza la especie de las comunidades autónomas o los entes administrativos de turno. La arbitrariedad de las adscripciones geográficas pesa sobre todo este problema y lo enturbia de forma lamentable. Proyectamos "la política" sobre "la historia", cuando justamente debería hacerse del revés.

\footnotetext{
6 « En estos no se permitió la convivencia de bosque, pradería, huerto, etc. del modo multifacético en que siempre se practicó en la franja norteña. Aquí se puede ver que no soy partidario del determinismo climático. Precisamente, el clima extremo, extremadamente seco, a veces semi-árido, que caracteriza la mayor parte de eso que se llama España no es un factum, no es un hecho bruto que hay que aceptar sin más y sobrevivir con él. Esa realidad tiene un origen antrópico, histórico. Las tendencias climáticas y geográficas de hace miles de años han sido agudizadas y extremadas por la acción vejatoria, depredadora, anti-natural, de los diversos pueblos o civilizaciones que han pasado por esas tierras." [íbid.]

7 Álvarez Junco (2001) Mater Dolorosa: la idea de España en el siglo XIX ,Taurus, Madrid, 2001.
} 
Los verdaderos protagonistas de la Historia no son los pueblos, son las culturas como unidades vitales que, en su último recorrido del ciclo, pasan a ser civilizaciones. Que por contingencias de la Historia misma, en un mismo Estado, como es el caso del de España, producto de la progresiva disminución de su vieja extensión como Imperio, coexistan pervivencias culturales del ámbito celtoatlántico y germánico, con pervivencias civilizadas del ámbito mediterráneo ("antiguo" y "arábigo") no es muy agradable a los bienpensantes actuales, a los censores de lo "políticamente correcto".

Solo existe nación en sentido faústico. Esta asimilación de gentes diversas (en lo racial, en el idioma, etc.) pero que conviven hasta llegar a parecerse, porque comparten lechos y experiencias, tras largos años de convivencia, comparten rasgos: esa la base para delimitarse bélicamente frente a otras naciones. Por debajo, y como efecto que esa experiencia compartida, una nación determinada imprime su propio carácter a una economía productiva. La casería astur (en embrión ya descrita por las fuentes romanas, pero conformada en el Asturorum Regnum), y sus análogas montañesa, vasca, galaica, es la unidad socioproductiva que se llevó a Castilla, hasta el Duero al menos, con las trasformaciones consiguientes que trajera el clima y el paisaje a medida que avanzaba la Reconquista-repoblación. Que un pequeño enjambre de pueblos productores-conquistadores, los pueblos del norte, conformados por la dinastía asturleonesa, hayan ido conquistando la España andalusí (es decir, no solo ni fundamentalmente la más mora sino también la más romana y bizantina), esto es, la parte "civilizada" (esclavista, urbanizada, capitalista) a lo largo de toda la Edad Media, es un hecho (o proceso que aglutina un sistema inmenso de hechos) ante el cual se estrellarán todas las Constituciones, todos los doceañistas rezagados, los liberales y los entusiastas del "hispanismo".

La cultura es la planta, la unidad viviente, que arraiga en un paisaje. Este paisaje, en el campo sin ciudades, imprime sus formas en el alma del hombre. Hay un misterioso poder del suelo, que determina rasgos somáticos y anímicos en los hijos que sobre él se crían. En el desarrollo de la cultura hay un largo periodo de vida aldeana, en el campo sin ciudades. $Y$ cuando aparece la ciudad ésta es una especie de excrecencia mercantil, jurídica y política a mayor gloria de la vida de las aldeas circundantes. Si se observa hoy qué es la capital de un concejo norteño en España, se verá que ese pequeño núcleo urbano (o a veces, todavía hoy, pre-urbano), debe arrogarse las funciones de cabeza de todo un dominio extenso de parroquias y aldeas diseminadas, incluso de unidades (en Asturies, caserías) prácticamente autosuficientes. La más antigua democracia "de vecinos" es la que tradicionalmente presidió la vida aldeana, acaso desde la Alta edad Media. Los señoríos nobles o eclesiásticos, el Rey y sus instituciones -siempre impostadas- son como nubes pasajeras que en poco afectaban -en términos sustanciales- a las viejas ordenanzas, usos, costumbres, fueros. Esta cultura hizo a los pueblos, y no a la inversa. Con la llegada del capitalismo y el predominio de la ciudad sobre el campo, los elementos más puros del campo trataron de no cortar raíces, en equipararse a la vida ciudadana. Fue la época inicial del capitalismo en la que la hidalguía norteña alcanzó los más altos niveles de preparación intelectual (Madrid, la Corte, nunca habría sido "moderna" sin asturianos y vascos que allí se asentaron). Esa especie de gentry ilustrada, muy dispar de la casta del 
terrateniente y rentista meridionales, seguían con un pie puesto en su vetusto caserón de piedra blasonado. En Asturies todavía hay casonas que son producto de la remodelación de viejos torreones medievales. En ellas, al menos parte del año, se escondían los tratados de Economía Política y Filosofía Política que, con el tiempo, los harían decaer en ruinas lamentables. Cuando Adam Smith o Rousseau se agazaparon en los anaqueles de aquella country gentry, el espíritu y el dinero comenzaron a vencer. El liberalismo, las "ideas modernas", la burguesía, el espíritu frente al alma.

En el momento en que la ciudad comienza a ganarle la partida al campo, la burguesía da la espalda a la comarca originaria: el poder del dinero adviene y se muestra sumamente desagradecido con el conocimiento (las "ideas modernas" en expresión de Nietzsche) que permitió su triunfo. La tierra cede ante el capital. Las casonas y castillos se abandonan, hay otros nidos de águila para el poder. Se alzan los bancos, las fábricas, los palacetes burgueses. El burgués difunde el mito del universalismo. Como el capital no posee acentos ni rasgos raciales, como el capital es cosmopolita, quiere uniformizar las culturas. El declinar de las culturas entonces está servido.

\section{La Técnica}

Pero este poder del dinero y éste sistema de la democracia burguesa sería inexplicable sin la Técnica. Desde que el hombre es hombre, hay en el mundo una técnica. La referencia a un homínido que altera el ambiente, que usa con sus manos los instrumentos y, más aún, los crea y transforma, es la clave de la técnica como último apartado en la evolución biológica. Pero la Técnica es plenamente Historia, y no el epifenómeno y capítulo último de la Historia Natural cuando se convierte en medio de poder, en el poder mismo. Solamente en la Cultura faústica los inventos han pasado de ser divertimentos a ser armas de dominación sobre la naturaleza y sobre otros hombres. Para que la Técnica cobre esa eficacia tan absoluta fue preciso organizar el mundo entero, la ciencia, la metafísica, la lógica, la moral, bajo esquemas de control y cómputo, como sistema de máquinas manipulables. La Técnica todopoderosa ya estaba organizada como sistema de control y cómputo mucho antes de que se desarrollaran las primeras máquinas complejas. Toda la orientación racionalista de la filosofía griega, con su entronización y aun divinización de las Matemáticas, el sistema conceptualista de los escolásticos, hasta llegar al racionalismo moderno. La historia del pensamiento pre-burgués es larga, y es una historia que se basa no en el dominio militar o depredador del mundo, sino en dominio controlador y manipulador del mundo. La ciencia es vejación, humillación de la Naturaleza (Bacon) y por ende es un sistema orientado por la Voluntad de Dominio. Pero no es dominadora con heroísmo: es dominante por previsión, cálculo y manipulación. Su afán, también fáustico, no entraña nada de riesgo. Su victoria es de índole universalista, "sacerdotal": se extiende por todo el Espacio, es puro espíritu pero ha perdido el alma.

La burguesía ha creado un sistema político burocrático hecho a su medida. Todo fue medido: se cuentan los billetes de banco como se cuentan los votos. Se juega, cada vez más con una óptica cesarista, el juego de la democracia: el 
pueblo ya no es el pueblo originario (Urwolk), sino el pueblo de ciudadanos. Cuando se habla de ciudadanos se habla de burgueses que emulan a la nobleza en querer ser el Estado mismo. Pero todo Estado es Estado de una clase. La burguesía precisó de la hez y de los "sin calzones" para derrocar una nobleza ya degradada. Pero cuando la burguesía es dueña de los resortes del poder, con el dinero amaña el formalismo democrático y el césar de turno (siempre surge uno) compra sus legiones de periodistas, educadores, demagogos. Como bien señala Spengler, la esclavitud del mundo burgués es la esclavitud de los lectores: hay que abrevar y rumiar lo que sus periódicas digan. Los libros son apartados a un lado más y más. Una opinión pública formada por lectores de libros -individualistas, no controlados- es sumamente peligrosa. Las escuelas de niños creadas por la burguesía quieren lectores de periódicos (y en la actualidad, ni eso, sino devoradores de micro-mensajes circulantes por las redes sociales de internet).

Pero el cesarismo que nos trajo la plutocracia burguesa es la condición misma de un resurgir de nuevas fuerzas que, en un primer momento, pueden aparecerse como primitivas e inconscientes. La fuerza de "la sangre", el poder de los hombres "de raza" son factores que no pueden dejar de manifestarse en una sociedad tan sumamente tecnificada y administrada. Pues el proyecto burgués consistente en jugar a la distinción entre sociedad civil y Estado deviene, a la postre, en aniquilación de la sociedad, supresión de jerarquías, de talentos, de excelencias, las fuerzas más primitivas y menos amables de la sangre y la raza no pueden por menos de expresarse en medio de una masa de hombres muelle, esclavos de la opinión pública y del cosmopolitismo decadente.

El hombre del mundo tecnificado se siente "en conexión" con todo un engranaje invisible que las nuevas tecnologías amplifican hasta extremos propios de la magia: no hay barreras espaciotemporales y se vive bajo la ilusión de contactar con "la sociedad". Pero precisamente por ello, cada vez se desconoce más y más en qué consiste "la sociedad". En realidad éste fue un invento de los sociólogos y, hoy, de los periodistas y políticos profesionales. Cuando Comte quiso hacer una ciencia de lo social, la Cultura Occidental ya entraba en su fase declinante de Civilización y el poder del dinero y de la democracia se gestó, desde las categorías de la Economía Política, como externalidades de un Mercado absoluto, lo que se quiso hacer, en realidad, fue una gran ocultación de la Historia. Le es preciso al mundo tecnificado llevar a cabo esa gran ocultación de la Historia. El ingeniero y el contable, revestidos con verdadera dignidad sacerdotal pretenden llenarnos el mundo con "sus" verdades. Pero las verdades se despeñan contra el torrente de los hechos. La Historia ofrece hechos, no quiere sistemas de conceptos ni utopías reformistas. Los sistemas de conceptos y los reformistas sociales siempre incurren en la nuda criminalidad, en el genocidio cuando se transforman en Voluntad de poder. Y como no posean suficiente Voluntad de poder se reducen al estado de impotencia: como dice Spengler, entonces se escriben libros de política, pero no se hace política. 